We thank Dr Martin Moncrieff for encouraging us to report this patient who was under his care, and for his helpful criticism of the manuscript.

1 Walker-Smith JA, Hamilton JR, Walker WA. Disorders of the stomach. Practical pediatric gastroenterology. London: Butterworth, 1983:174-84.

2 Decklebaum RJ, Roy CC, Lussier-Lazaroff J, Morin CL
Peptic ulcer disease: a clinical study in 73 children. Can Med Assoc F 1974;111:225-8.

3 Seagram CGF, Stephens CA, Cumming WA. Peptic ulceration at the Hospital for Sick Children, Toronto 1949-1969. $\mathcal{f}$ Pediatr Surg 1973;8:407-13.

4 Nord KS, Lebenthal E. Peptic ulcer in children: a review. Am $\mathcal{Y}$ Gastroenterol 1980;73:75-80.

5 Silverman A, Roy CC. Disorders of the stomach and duodenum. Pediatric clinical gastroenterology. St Louis: CV Mosby, 1983:162-89.

6 Hsu HY, Chang MH, Wang TH, et al. Acute duodenal ulcer. Arch Dis Child 1989;64:774-9.

\title{
An unusual cause of thoracic mass
}

\author{
D C Wilson, A O B Redmond
}

\begin{abstract}
A previously well 10 year old boy presented with scoliosis, a mass in the chest wall, and a pleural effusion. Chest radiography showed the triad of chronic consolidation, pleural effusion, and rib periostitis. Investigations confirmed thoracic actinomycosis. Tissue spread was evaluated by computed tomography. It was successfully treated with benzylpenicillin, which was later replaced by clindamycin.
\end{abstract}

Thoracic actinomycosis is extremely rare in children, especially if they are immunocompetent, and is not often considered in the differential diagnosis of paediatric pulmonary disease. This case illustrates the typical presentation, classic radiological and microbiological findings, and treatment of this subacute infection.

\section{Case report}

A 10 year old boy presented with lethargy, weight loss, and chest pain. A submandibular swelling and a mass in the chest wall had been noted recently. He had no history of anorexia, sweats, cough, fever, or sputum, but had mild asthma; he had not been in contact with tuberculosis.

He looked ill, but had no fever, lymphadenopathy, or rash. His weight was on the tenth centile. He had dental caries and diffuse swelling of the left submandibular area. There was a central abscess within a large, indurated, tender swelling of his left lower anterior chest wall. He had thoracic scoliosis, diminished expansion, dullness to percussion, and a patch of bronchial breathing with scattered crepitations at the left base. Liver and spleen were not enlarged.

Results of investigations included haemoglobin concentration $99 \mathrm{~g} / \mathrm{l}$, white cell count $16.3 \times 10^{9} / 1$, neutrophil count $13.7 \times 10^{9} / 1$, erythrocyte sedimentation rate $42 \mathrm{~mm}$ in the first hour, and $C$ reactive protein concentration 73 $\mathrm{mg} / \mathrm{l}$ (reference range $<6$ ). A chest radiograph showed thickening of the left chest wall, consolidation of the left lower lobe, left pleural effusion, and periostitis of the left seventh and

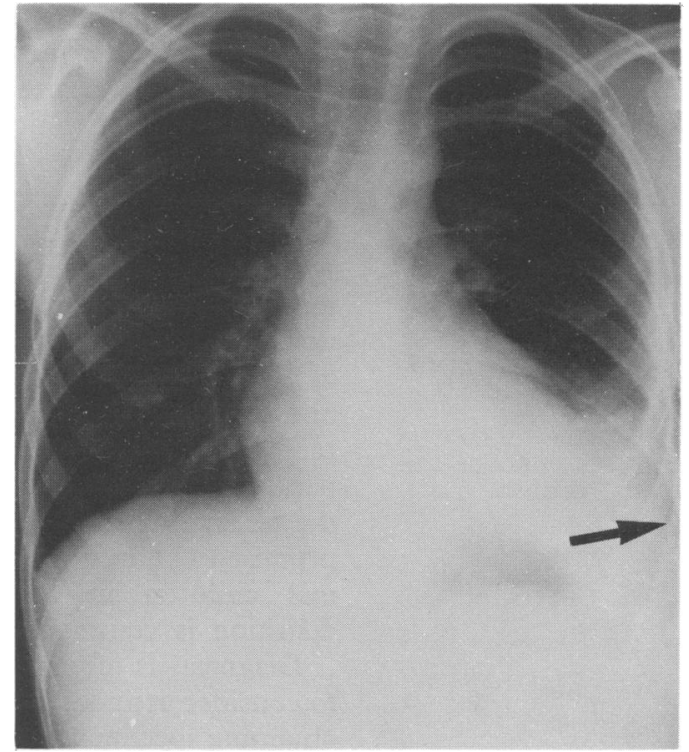

Chest radiograph showing triad of chronic consolidation, pleural effusion, and rib periostitis (arrowed).

eighth ribs (figure). A computed tomogram of the thorax showed a lesion spreading from the left lower lobe of the lung to the pleura, invading the ribs, and then passing through the chest wall. Radiographs of the mandible, abdominal ultrasound scan, liver function tests, and immunological screen were normal. Blood cultures grew no pathogens and a Mantoux test was negative.

When the abscess pointed, it was incised. Examination of the pus showed sulphur granules and Gram positive branching filaments with clubs; Actinomyces israelii was grown. High doses of benzylpenicillin were given intravenously, and four carious teeth extracted. After two weeks the erythrocyte sedimentation rate was $14 \mathrm{~mm} /$ in the first hour and $C$ reactive protein concentration $7 \mathrm{mg} / \mathrm{l}$. One week later, as he had developed urticaria, clindamycin was substituted for benzylpenicillin. After five weeks of parenteral treatment, he was discharged taking clindamycin orally. This was continued for eight months and during this time his weight increased and the chest signs resolved. A
Accepted 5 April 1990

(Arch Dis Child 1990;65:991-2) 
further chest radiograph showed only a small residual pleural effusion.

\section{Discussion}

Invasive actinomycosis affects the cervicofacial region in $65 \%$ of cases, the abdomen in $20 \%$ of cases, and the thorax in only $15 \%$ of cases. Thoracic actinomycosis is rare in childhood; we could find only two reports of its occurrence in the United Kingdom. ${ }^{12}$ Lack of familiarity with the disease by both clinicians and radiologists may, however, lead to diagnostic error.

Actinomyces is a normal commensal of the human mouth. Pulmonary actinomycosis may result from infection from several sourcesaspiration from the oral cavity, carriage into the lung on a foreign body, haematogenous seeding, or spread of existing cervicofacial or abdominal infection through the tissue planes. ${ }^{3}$ Actinomyces are Gram positive, non-acid fast bacilli, and are facultative anaerobes. They are true bacteria, although they were previously classified with fungi because of their mycelial appearance and indolent clinical course. $A$ israelii is the most common species, although there are others such as Actinomyces meyerii that can cause similar disease.

The clinical features in this case are characteristic of actinomycosis. Actinomyces infections do not respect tissue planes; the complex of pulmonary, pleural, and chest wall disease is unusual with other infections. ${ }^{4}$ Actinomycosis is rare in normal children, because dental caries or peridontitis are usually followed by rapid loss of the teeth. ${ }^{5}$ It is more common in immunocompromised children, or among mentally subnormal children in institutions, ${ }^{2}$ where poor dentition is common.

Diagnosis is often delayed because of failure to consider actinomycosis, and the difficulty in obtaining specimens and culturing them anaerobically. Examination of pus may show sulphur granules, which are suggestive but not diagnostic of actinomycosis. Microscopic examination shows Gram positive branching filaments with terminal clubs, but often the organism is not seen after anaerobic culture. Recovery of the organism from sputum means nothing, as it is a normal oral commensal. The classic radiological presentation of thoracic actinomycosis is the triad of chronic consolidation, pleural effusion, and overlying rib periostitis as was seen in this case. ${ }^{2}$ Periostitis indicates chronic infection, rather than destruction by acute infection or malignancy. Computed tomography is useful in evaluating the lesion. ${ }^{6}$ The differential diagnosis is wide, and includes tuberculosis, lung abscess, carcinoma, reticulosis, and atypical pneumonia. ${ }^{35}$

The use of antibiotics in the treatment of actinomycosis has resulted in a high rate of cure, even in advanced disease, and the most appropriate drug is penicillin. ${ }^{3}$ There is no agreement, however, about dosage or duration of treatment. Parenteral penicillin is usually given for several weeks, followed by penicillin orally for three to six months. In some centres high doses of oral penicillin alone have been used. ${ }^{4}$ Other antibiotics have also been used successfully, including erythromycin, chloramphenicol, clindamycin, and lincomycin, particularly in cases of allergy to penicillin.

Prognosis is excellent when diagnosis has been reached and specific antibiotics used. Mortality in the past was related to late diagnosis, haematogenous spread, and injudicious surgical intervention.

1 Drake DP, Holt RJ. Childhood actinomycosis. Report of three recent cases. Arch Dis Child 1976;51:979-81.

2 Thompson AJ, Carty H. Pulmonary actinomycosis in children. Pediatr Radiol 1979;8:7-9.

3 Medoff G, Kobayashi G. Pulmonary infections due to actinomyces and nocardia, and pulmonary mycoses. In: Reigin RD, Cherry ID eds. Textbook of pediatric infections Reigin RD, Cherry JD, eds. Textbook of pediatric infectious diseases. 2nd Ed. Philadelphia: WB Saunders, 1987:300-2. acic actinomycosis. Pediatr Infect Dis 1986;5:594-5.

acic actinomycosis. Pediatr Infect Dis 1986;5:594-5. ennhoff DF. Actinomycosis: diagnostic and therapeutic consideration

6 Golden N, Cohen H, Weissbrot J, Silverman S. Thoracic actinomycosis in childhood. Clin Pediatr 1984;24:646-50.

\title{
Spontaneous resolution of congenital nephrotic syndrome in a neonate
}

\author{
C R Banton, B Thalayasingam, M G Coulthard
}

\section{Shotley Bridge \\ General Hospital, Consett, \\ Co Durham \\ C R Banton \\ B Thalayasingam \\ Royal Victoria Infirmary, Newcastle upon Tyne \\ NE1 4LP \\ M G Coulthard \\ Correspondence to: Dr Coulthard.}

Accepted 24 April 1990

(Arch Dis Child 1990;65;992-3).

\begin{abstract}
An infant with congenital nephrotic syndrome recovered spontaneously and completely by the age of 11 days and had remained well at the age of 1 year. This reinforces the view that reversible congenital nephrotic syndrome does occur and that it is not a single disease with a universally dismal prognosis.
\end{abstract}

Congenital nephrotic syndrome presents in the first three months of life, ${ }^{12}$ and usually results in death in early childhood unless intensive treatment including renal transplantation is undertaken. ${ }^{1-3}$

Only four cases of congenital nephrotic syndrome with spontaneous recovery have previously been reported, and of these two did so at 10 and 25 months. ${ }^{13}$ The other two were siblings whose mother had focal segmental glomerulosclerosis and were presumed to have been affected by humoral factors; they recovered in less than three weeks. ${ }^{4}$ 